\title{
PENGGUNAAN PHENOXY ETHANOL, SUHU DINGIN, DAN KOMBINASI SUHU DINGIN DENGAN PHENOXY DALAM PEMBIUSAN BANDENG UMPAN
}

\author{
Suwardi Tahe ${ }^{*}$ \\ *) Balai Riset Perikanan Budidaya Air Payau, Maros
}

\begin{abstract}
ABSTRAK
Usaha penangkapan tuna dan cakalang semakin berkembang dan penggunaan bandeng umpan hidup kian marak. Kendala dalam penanganan umpan hidup adalah penanganan sewaktu panen dan pengangkutan sampai kelokasi penangkapan. Untuk itu telah dilakukan pengangkutan bandeng umpan dengan phenoxy ethanol ( $200 \mathrm{mg} / \mathrm{L})$, suhu dingin $\left(23^{\circ} \mathrm{C}\right)$, dan kombinasi suhu dingin dengan phenoxy ethanol dalam berbagai kepadatan yaitu 5, 10, dan 15 ekor/5L yang dirancang dengan acak lengkap pola faktorial masing-masing tiga ulangan. Hasil penelitian menunjukkan bahwa jumlah kepadatan yang baik adalah berkisar 5--10 ekor/ $5 \mathrm{~L}$ dan pengangkutan dengan suhu dingin dan kombinasi suhu dingin dan phenoxy ethanol dapat diaplikasikan oleh pengguna, karena sintasan didapat antara 90\%-100\%dengan durasi sedatif 6 jam.
\end{abstract}

\section{KATA KUNCl: phenoxy ethanol, suhu rendah, milk fish}

\section{PENDAHULUAN}

Ikan bandeng (Chanos chanos) merupakan satu di antara komoditas utama pertambakan di Indonesia, karena selain dikonsumsi, digunakan juga sebagai umpan hidup bagi kegiatan penangkapan ikan tuna (Thunnus alalunga) dan cakalang (Katsuwonus pelamis) dengan huhate (poleand line). Umpan hidup merupakan faktor pembatas dalam penangkapan tuna dan cakalang, karena itu dipilih umpan hidup berkualitas baik.

Ikan bandeng dapat memenuhi persyaratan sebagai umpan dalam penangkapan tuna dan cakalang karena dapat diproduksi di tambak dan KJA, mampu hidup berjejal, tahan terhadap penyakit serta benihnya tersedia sepanjang tahun (Cholik \& Pasaribu, 1989). Dalam operasi penangkapan ikan, umpan hidup sangat berpengaruh terhadap hasil tangkapan, sehingga penanganan umpan hidup ke daerah operasi penangkapan perlu diperhatikan. Salah satu cara yang dapat dilakukan adalah pembiusan terhadap umpan hidup yang bertujuan untuk menenangkan ikan, mengurangi aktivitasnya, dan laju metabolisme.

Obat bius adalah senyawa kimia yang dapat menyebabkan hilangnya seluruh atau sebagian rasa sebagai akibat dari penurunan fungsi sel (Schreck \& Moyle, 1990). Dalam transportasi ikan harus dilakukan secara hati-hati, karena kesalahan dalam penanganan dapat menyebabkan kematian yang dapat menimbulkan kerugian baik tenaga, waktu maupun biaya (Huet, 1972). Untuk kepentingan hal tersebut, maka faktor-faktor seperti spesies ikan, umur, ukuran, daya tahan, lama pengangkutan, dan kondisi iklim perlu diperhatikan. Selain itu, jenis obat bius yang digunakan sedapat mungkin memiliki daya bius yang cepat dan mudah terurai kembali. Penggunaan phenoxy ethanol telah banyak digunakan untuk kegiatan sampling, dan tagging ikan percobaan, begitu pula penggunaan suhu rendah telah lama dipraktekkan dan transportasi benih ikan dan udang. Informasi tentang efek sedatif obat phenoxy ethanol dan kombinasi dengan suhu dingin belum diketahui. Untuk itu telah dilakukan percobaan pengangkutan bandeng umpan hidup dengan menggunakan obat bius phenoxy ethanol, dan suhu rendah dengan tujuan untuk mengetahui pengaruh phenoxy ethanol, suhu rendah dan kombinasi suhu rendah, serta phenoxy ethanol terhadap lama waktu pingsan dan sintasan ikan.

\section{BAHAN DAN METODE}

Penelitian dilakukan di Laboratorium Basah Instalasi Tambak Percobaan Maranak, Maros. Hewan uji yang digunakan adalah ikan bandeng kisaran ukuran panjang total dan bobot masing-masing $15--17 \mathrm{~cm}$ dan $60--80 \mathrm{~g}$. Penelitian dirancang dengan Rancangan Acak Lengkap (RAL) dengan perlakuan pola faktorial yaitu phenoxy ethanol $(200 \mathrm{mg} / \mathrm{L})$ dan suhu dingin $\left(23^{\circ} \mathrm{C}\right)$, kombinasi phenoxy ethanol + suhu dingin serta kepadatan 5, 10, dan 15 ekor/5L, masing-masing diulang 3 kali.

Wadah percobaan berupa kantong plastik berukuran panjang dan lebar masing-masing $80 \mathrm{~cm}$ dan $50 \mathrm{~cm}$. Setiap kantong diisi sebanyak 5 liter air payau salinitas 15\% 
untuk menjamin ketersediaan oksigen terlarut dalam kantong plastik, maka setiap kantong diisi oksigen murni dengan perbandingan antara air dan oksigen masingmasing 1:2 (Bocek, 1992), kemudian kantong tersebut diikat dengan karet gelang agar air dan oksigen dalam kantong tidak habis.

Peubah yang diamati selama pembiusan adalah waktu induksi ikan dan lama waktu sedatif (sedative duration). Kriteria ikan pingsan yang dianjurkan untuk ditransportasikan berada pada fase I.b (deep sedative) menurut Mc Farland (1960) dalam Piper et al. (1982). Sintasan pada akhir penelitian dihitung dengan rumus Effendie (1979). Data dianalisis secara statistik untuk mengetahui pengaruh dosis phenoxy ethanol, suhu dingin, serta kombinasi suhu dingin dan phenoxy ethanol terhadap sintasan yang diperoleh pada akhir percobaan. Sedangkan peubah kualitas air sebagai parameter kunci yang sangat menentukan sintasan ikan selama penelitian diamati pada akhir penelitian (saat ikan siuman) meliputi oksigen terlarut, $\mathrm{CO}_{2}$ bebas, amoniak, suhu, dan $\mathrm{pH}$, selanjutnya dibahas secara deskriptif.

\section{HASIL DAN BAHASAN}

Keragaan hewan uji setelah dimasukkan dalam media percobaan memperlihatkan bahwa pada mulanya ikan dalam kondisi tenang di dasar, beberapa detik kemudian gerakannya gelisah, terkadang naik dan turun, bahkan sering mulutnya membentur wadah/kantong. Sebelum ikan pingsan kerap kali ikan naik ke permukaan dengan gerakan tutup insang yang sangat cepat, seiring dengan itu ikan tidak bisa lagi mengendalikan fungsi normalnya sehingga ikan melayang dan jatuh ke dasar. Setelah itu, ikan dinyatakan pingsan yang ditandai dengan posisi terlentang disertai gerakan operculum yang semakin lamban. Hal yang demikian terjadi pada semua perlakuan.
Dalam keadaan seperti ini ikan tidak lagi bergerak, tetapi tutup insang tetap bergerak.

Hasil pengamatan menunjukkan bahwa semakin padat ikan dalam kantong maka sintasan semakin menurun (Tabel 1). Bahkan pada tingkat kepadatan 15 ekor/L baik pada penggunaan phenoxy maupun suhu dingin serta percampuran suhu dingin dan phenoxy kematian mencapai $100 \%$ Hasil pengamatan pada saat ikan dimasukkan ke kantong dengan kepadatan 15 ekor/L, tampak bahwa aktivitas renang meningkat, sehingga dalam waktu kurang dari 5 menit wadah dalam kantong didominasi oleh busa air yang diduga dari lendir ikan, sehingga kematian hewan uji diduga karena kepadatan ikan dan kelarutan oksigen yang terlarut oleh busa air. Berdasarkan uji statistik menunjukkan bahwa pada perlakuan pembiusan dengan phenoxy ethanol, suhu dingin, dan phenoxy + suhu dingin dengan kepadatan 5 ekor/L tidak menunjukkan perbedaan yang nyata $(P<0,05)$. Tetapi pada kepadatan 10 ekor/L dengan perlakuan suhu dingin dan phenoxy + suhu dingin berbeda nyata $(P>0,05)$ dengan pembiusan dengan phenoxy ethanol. Apabila dikaitkan dengan waktu sedatif ternyata bahwa kepadatan 10 ekor/5L lama pingsan 6 dan 8 jam tidak berbeda nyata $(P<0,05)$ tetapi berbeda pada lama pingsan 4 jam.

Penggunaan phenoxy ethanol setelah 8 jam sintasan menurun drastis menjadi $23,33 \%$ pada perlakuan kepadatan 10 ekor/5L, sedangkan pada durasi 6 jam pengangkutan sintasan masih sekitar $70 \%$ Hasil penelitian ini lebih rendah dibandingkan dengan hasil penelitian Daud et al. (1997) yaitu 100\%selama 332 menit menggunakan MS-222. Sedangkan Suwardi et al. (1999) dengan menggunakan minyak cengkeh mendapatkan hasil sintasan juga 100\%dengan durasi sedatif 302 menit. Hal ini diduga disebabkan oleh karakteristik obat bius yang digunakan berbeda, selain itu kepadatan ikan yang

Tabel 1. Sintasan (\%) bandeng umpan menurut lama pengangkutan menggunakan phenoxy ethanol dan suhu dingin pada kepadatan berbeda

\begin{tabular}{lcccc}
\hline & & \multicolumn{3}{c}{ Lama pengangkutan (jam) } \\
\cline { 2 - 5 } Perlakuan anestesi & 5 & $\mathbf{4}$ & $\mathbf{6}$ & $\mathbf{8}$ \\
\hline & 10 & $100^{\mathrm{a}}$ & $100^{\mathrm{a}}$ & $93,33^{\mathrm{a}}$ \\
Phenoxy ethanol $(200 \mathrm{mg} / \mathrm{L})$ & 15 & $100^{\mathrm{a}}$ & $70^{\mathrm{b}}$ & $23,33^{\mathrm{c}}$ \\
& 5 & $33,33^{\mathrm{b}}$ & 0 & 0 \\
\hline & 10 & $100^{\mathrm{a}}$ & $100^{\mathrm{a}}$ & $86,67^{\mathrm{a}}$ \\
Suhu dingin $\left(23^{\circ} \mathrm{C}\right)$ & 15 & $100^{\mathrm{a}}$ & $80^{\mathrm{b}}$ & $60^{\mathrm{b}}$ \\
& 5 & $40^{\mathrm{b}}$ & 0 & 0 \\
\hline \multirow{3}{*}{ Phenoxy ethanol $(200 \mathrm{mg} / \mathrm{L})+$} & 10 & $100^{\mathrm{a}}$ & $100^{\mathrm{a}}$ & $80^{\mathrm{a}}$ \\
suhu dingin $\left(23^{\circ} \mathrm{C}\right)$ & 15 & $100^{\mathrm{a}}$ & $90^{\mathrm{ab}}$ & $65^{\mathrm{b}}$ \\
& & $42,22^{\mathrm{b}}$ & 0 & 0 \\
\hline
\end{tabular}


digunakan juga berbeda. Kualitas air sebagai penunjang pada penelitian ini dapat dilihat pada Tabel 2.

Dari Tabel 2 terlihat bahwa kadar oksigen pada akhir penelitian cenderung menurun, akan tetapi kandungannya masih layak bagi kehidupan ikan. Menurut Chervinski (1982), batas terendah kandungan oksigen yang dapat ditolerir oleh ikan adalah 0,1 mg/L. Djajadiredja et al. (1980) menyebutkan perairan yang mempunyai kandungan oksigen terlarut sama atau lebih tinggi dari 5 $\mathrm{mg} / \mathrm{L}$ merupakan media yang baik untuk ikan air tawar.
Swingle (1960) dalam Hickling (1971) berpendapat bahwa ikan mas dapat hidup pada keasaman pH antara 6,5--9,0. Pada $\mathrm{pH}$ di atas 9,5 perairan sudah tidak produktif lagi karena terlalu basa, dan pada pH di bawah 4,0 ikan mas akan mati. Menurut Djajadiredja et al. (1986), budidaya intensif akan berhasil dengan memuaskan jika perairan mempunyai kisaran $\mathrm{pH}$ antara 7,5 dan 8,5 karena suasana sedikit basa akan mempertinggi selera makan ikan.

Suhu air media selama penelitian berkisar $23,3^{\circ} \mathrm{C}--$ $28,4^{\circ} \mathrm{C}$ pada akhir penelitian. Keadaan suhu tersebut

Tabel 2. Kualitas air setelah 8 jam pengangkutan menggunakan obat bius dan suhu dingin pada kepadatan berbeda

\begin{tabular}{lcccccc}
\hline Perlakuan anestesi & Kepadatan & $\mathbf{D O}$ & $\mathbf{C O}_{\mathbf{2}}$ & $\mathbf{N H}_{\mathbf{3}}$ & $\mathbf{p H}$ & $\mathbf{S u h u}$ \\
\hline \multirow{3}{*}{ Phenoxy ethanol $(200 \mathrm{mg} / \mathrm{L})$} & 5 & 4,3 & 70,45 & 0,0760 & 6,4 & 28,0 \\
& 10 & 3,8 & 68,32 & 0,0864 & 6,0 & 28,0 \\
& 15 & 4,3 & 70,34 & 0,0478 & 6,3 & 28,3 \\
\hline \multirow{3}{*}{ Suhu dingin $\left(23^{\circ} \mathrm{C}\right)$} & 5 & 3,9 & 53,41 & 0,0756 & 6,2 & 23,4 \\
& 10 & 4,0 & 59,47 & 0,4953 & 6,0 & 23,6 \\
& 15 & 4,1 & 60,35 & 0,0673 & 6,1 & 23,9 \\
\hline \multirow{2}{*}{ Phenoxy ethanol $(200 \mathrm{mg} / \mathrm{L})+$ suhu } & 5 & 3,9 & 36,45 & 0,0353 & 6,3 & 23,0 \\
dingin $\left(23^{\circ} \mathrm{C}\right)$ & 10 & 4,2 & 51,32 & 0,0545 & 6,2 & 23,5 \\
& 15 & 4,3 & 60,42 & 0,0921 & 6,0 & 23,7 \\
\hline
\end{tabular}

Stickney (1979) berpendapat bahwa tingkat kandungan semacam itu tidak akan menimbulkan stres bagi hewan budidaya. Itazawa (1968) dalam Alabaster \& Lloyd (1980) berpendapat bahwa untuk mempertahankan pertumbuhan, nafsu makan, dan konversi makanan pada tingkat yang baik bagi ikan mas, maka kadar oksigen terlarut seharusnya tidak lebih rendah dari $3 \mathrm{mg} / \mathrm{L}$ pada suhu $21,3^{\circ} \mathrm{C}$.

Konsentrasi $\mathrm{CO}_{2}$ yang tinggi dapat menyebabkan narcotic effect pada ikan tetapi bila terlampau tinggi dapat mematikan ikan (Boyd, 1990). Selanjutnya dikatakan kadar $\mathrm{CO}_{2} 10 \mathrm{mg} / \mathrm{L}$ masih dapat ditolerir oleh ikan asalkan kadar oksigen tinggi. Sedangkan Wardoyo (1981) menyarankan bahwa kadar $\mathrm{CO}_{2}$ dalam air sebaiknya lebih rendah dari $5 \mathrm{mg} / \mathrm{L}$. Dalam penelitian ini kadar $\mathrm{CO}_{2}$ akhir berkisar 36,45--70,45 mg/L. Sebenarnya kadar tersebut sudah sangat berbahaya bagi ikan bila kadar oksigen rendah. Hanya saja dalam pengangkutan sistem tertutup kadar oksigen tetap tinggi yaitu 3,8--4,3 mg/L (Tabel 2).

Derajat keasaman $(\mathrm{pH})$ air juga mempengaruhi pertumbuhan ikan. Derajat keasaman yang diperoleh selama penelitian berkisar 6,0--6,4. Huet (1972) menyatakan bahwa perairan yang produktif dan ideal bagi kehidupan ikan, keasamannya adalah antara 6,5--8,5. masih layak untuk kehidupan ikan bandeng. Huet (1972) berpendapat bahwa suhu air mempengaruhi pertumbuhan ikan, suhu optimal untuk pertumbuhan ikan mas bervariasi antara $23^{\circ} \mathrm{C}$ dan $30^{\circ} \mathrm{C}$. Selanjutnya Djajadiredja et al. (1980) berpendapat bahwa suhu merupakan satu di antara faktor penting bagi lingkungan hidup perairan, karena suhu tinggi dapat mengurangi jumlah oksigen terlarut dan nafsu makan ikan. Dalam hubungan ini Wardoyo (1981) menyatakan bahwa suhu optimal untuk pertumbuhan ikan terletak antara $25^{\circ} \mathrm{C}$ dan $27^{\circ} \mathrm{C}$ dan bahkan nafsu makan ikan menurun apabila suhu air meningkat.

Kadar amoniak $\left(\mathrm{NH}_{3}\right)$ pada media penelitian berkisar 0,0353--0,4953 mg/L pada akhir penelitian. Pada awal penelitian kadar amoniak dianggap masih layak untuk organisme uji tetapi pada akhir penelitian kadar amoniak sudah sangat membahayakan. Menurut Djajadiredja et al. (1986), perairan yang mengandung kadar amoniak tidak lebih dari 0,1 mg/L dianggap perairan normal. Sedangkan jika mengandung lebih dari $1 \mathrm{mg} / \mathrm{L}$ dianggap perairan tercemar. Selanjutnya Pescod (1973) menyatakan bahwa kadar amoniak yang layak untuk ikan-ikan di perairan tropis dan organisme lainnya adalah kurang dari $0,1 \mathrm{mg} /$ L. Menurut Spotte (1970), daya racun $\mathrm{NH}_{3}$ sangat 
dipengaruhi oleh kandungan oksigen dan $\mathrm{pH}$ air. Sedangkan Alabaster \& Lloyd (1980) berpendapat bahwa pengaruh yang berbahaya dari amoniak adalah berhubungan erat dengan nilai pH dan suhu air. Dengan meningkatnya nilai $\mathrm{pH}$ dan suhu air, maka daya racun $\mathrm{NH}_{3}$ akan meningkat pula.

\section{KESIMPULAN}

Dari hasil percobaan dapat disimpulkan bahwa jumlah kepadatan yang baik adalah berkisar 5--10 ekor/5L dan pengangkutan dengan suhu dingin $\left(23^{\circ} \mathrm{C}\right)$ serta kombinasi suhu dingin dan phenoxy ethanol (200 mg/L) dapat diaplikasikan oleh pengguna. Karena sintasan yang diperoleh antara 90\%-100\%dengan durasi sedatif 6 jam.

\section{DAFTAR PUSTAKA}

Alabaster, J.S. and R. Lloyd. 1980. Water quality criteria for freshwater fish. Butter Worths, London. Boston. $283 \mathrm{pp}$.

Bocek, A. 1992. Pengangkutan ikan. Pedoman Teknis Proyek Penelitian dan Pengembangan Perikanan. Pusat Penelitian dan Pengembangan Perikanan. Jakarta. 17 pp.

Boyd, C.E. 1990. Water quality management for fish culture. Auburn University. Alabama. 359 pp.

Chervinski, J. 1982. Environmental physiology of Tilapia. In R.S.V. Pullin and R.H.Lowe Mc Connel (Eds.). The biology and culture of Tilapia. ICLARM Conference Proceedings. 7, 432 p. International Center for Living Aquatic Resource Management Manila, Philippines. p. 119- 128.

Cholik, F. dan A.M. Pasaribu. 1989. Budidaya Bandeng umpan, Prospek dan Permasalahannya. Balai Penelitian Perikanan Pantai Maros. 15 pp.

Daud, R., Suwardi, M.J.R Yakob, dan Utojo. 1997. Penggunaan MS-222 (Tricaine Methane Sulfonate) untuk pembiusan ikan bandeng (Chanos chanos Forskall) umpan. J. Pen. Perik. Indonesia. 3(3): 4751.

Djajadiredja, R., Z. Jangkaru, dan S. Omiarso. 1980. Mekanisme dalam usaha peningkatan daya guna air tawar untuk budidaya ikan secara intensif. Lokakarya Nasional Teknologi Tepat Guna Bagi Pengembangan Air Payau. Lembaga Penelitian Perikanan Darat. Bogor. $9 \mathrm{pp}$.

Djajadiredja, R., Z. Jangkaru, dan S. Omiarso. 1986. Mekanisme dalam usaha peningkatan daya guna air tawar untuk budidaya ikan secara intensif. Lokakarya Nasional Teknologi Tepat Guna Bagi Pengembangan Air Tawar. Balitkanwar Bogor. p. 143- 151.

Effendie, M.I. 1979. Metode Biologi Perikanan. Yayasan Dewi Sri Bogor. 112 pp.

Hickling, C.F. 1971. Fish culture. Faber and Faber. London. 317 pp.

Huet, M. 1972. Text book of fish culture. Breeding and Cultivation of Fish. Fishing News (Book) Ltd. London. 317 pp.

Pescod, M.B. 1973. Investigation of rational effluent and stream standard for tropical countries. Asian Institute of Technology, Bangkok Thailand. 59 pp.

Piper, G.R., Mc Elwain, I.B Orme L.E., Mc Craren J.P., Fowler L.C., and Leonard J.R. 1982. Fish hatchery Management. United States Department of Interior. Washington D.C. 517 pp.

Schrek, C.B. and Moyle. 1990. Method of fish biology American Fisheries Society Bathesda Mariland. USA. $684 \mathrm{pp}$.

Spotte, S. 1970. Fish and invertebrate culture. John Willey and Sons, New York, London, Sydney, Toronto. $143 \mathrm{pp}$.

Stickney, R.R. 1979. Principle of warm water aquaculture. John Willey and Sons, New York, Chichester, Brisbane, Toronto. 375 pp.

Suwardi, R. Daud, dan M.J.R Yakob 1999. Penggunaan minyak cengkeh sebagai obat bius dalam transportasi bandeng (Chanos chanos) umpan hidup. J. Pen. Perik. Indonesia. 5(2): 75-80

Wardoyo, S.T.H. 1981. Kriteria kualitas air untuk keperluan perikanan dan pertanian. PPLH-PUSDI-PSL. Institut Pertanian Bogor. 40 pp. 